\title{
OPEN Reference gene selection for expression studies in the reproductive axis tissues of Magang geese at different reproductive stages under light treatment
}

\author{
Bei-Bei Zhang, Xu Shen, Xiu-Jin Li, Yun-Bo Tian, Hong-Jia Ouyang ${ }^{\bowtie}$ \& Yun-Mao Huang
}

In quantitative PCR research, appropriate reference genes are key to determining accurate mRNA expression levels. In order to screen the reference genes suitable for detecting gene expression in tissues of the reproductive axis, a total of 420 (males and females = 1:5) 3-year-old Magang geese were selected and subjected to light treatment. The hypothalamus, pituitary and testicular tissues were subsequently collected at different stages. Ten genes including HPRT1, GAPDH, ACTB, LDHA, SDHA, $B 2 M, T U B B 4, T F R C, R P S 2$ and RPL4 were selected as candidate reference genes. The expression of these genes in goose reproductive axis tissues was detected by real-time fluorescent quantitative PCR. The $\triangle C T$, geNorm, NormFinder and BestKeeper algorithms were applied to sort gene expression according to stability. The results showed that $A C T B$ and TUBB4 were the most suitable reference genes for the hypothalamic tissue of Magang goose in the three breeding stages; HPRT1 and RPL4 for pituitary tissue; and HPRT1 and $\angle D H A$ for testicular tissue. For all three reproductive axis tissues, $A C T B$ was the most suitable reference gene, whereas the least stable reference gene was GAPDH. Altogether, these results can provide references for tissue expression studies in geese under light treatment.

The reverse transcription quantitative real-time polymerase chain reaction (RT-qPCR) is a method of quantitative analysis using a starting template and evaluating the relationship between cycle threshold (Ct) values and a standard curve ${ }^{1}$. Given its rapidity, sensitivity, specificity and high flux, this method has been recognized as the benchmark approach for quantify and validate gene expression. However, the RNA yield, quality, reverse transcription efficiency, and PCR amplification efficiency among different samples all affect the accuracy of quantitative analysis; thus, introduction of the stable expression of reference genes for normalization is necessary ${ }^{2,3}$.

Stable reference genes are the key to accurate quantification of gene expression ${ }^{4,5}$. An ideal reference gene would show stable expression for a particular tissue type, independent of the developmental stage or experimental treatment conditions. Such as $A C T B$ and GAPDH are widely used as common reference genes. However, a large number of studies have shown that the expression of these genes may not be consistent under various experimental conditions and in various tissues under investigation ${ }^{6-8}$. Therefore, it is better to screen appropriate reference genes in expression research, especially under specific experimental treatment conditions.

At present, many mathematical algorithms have been developed to facilitate the identification of stable internal reference genes, including the geNorm, NormFinder and BestKeeper programs ${ }^{4,9,10}$. Many studies have reported the evaluation of reference genes in different tissues of poultry at different physiological stages. Carlos et al. ${ }^{11}$ reported that $H M B S$ and HPRT1 are the most stable reference genes in the pectoralis major muscle of 1-day-old chicken. Caroline et al. ${ }^{12}$ identified 10 genes from the pectoral muscle of broilers, among which RPL30 and RPL5 were the most stable genes. Zhang et al. ${ }^{13}$ studied the expression stability of four candidate internal 


\begin{tabular}{|l|l|l|l|l|l|l|}
\hline No & Gene symbol & Ta $\left({ }^{\circ} \mathbf{C}\right)$ & Amplicon size (bp) & Efficiency (\%) & Correlation coefficient $\left(\mathbf{R}^{2}\right)$ & Slope \\
\hline 1 & HPRT1 & 53.0 & 112 & 107.615 & 0.985 & -3.152 \\
\hline 2 & LDHA & 55.0 & 124 & 100.361 & 0.990 & -3.313 \\
\hline 3 & SDHA & 55.0 & 159 & 97.513 & 0.998 & -3.383 \\
\hline 4 & B2M & 56.0 & 175 & 98.149 & 0.990 & -3.367 \\
\hline 5 & TUBB4 & 57.0 & 208 & 94.980 & 0.982 & -3.448 \\
\hline 6 & TFRC & 57.0 & 206 & 107.117 & 0.997 & -3.162 \\
\hline 7 & RPS2 & 58.0 & 224 & 99.499 & 0.994 & -3.334 \\
\hline 8 & RPL4 & 58.0 & 198 & 95.366 & 0.986 & -3.438 \\
\hline 9 & ACTB & 58.0 & 92 & 92.845 & 0.997 & -3.506 \\
\hline 10 & GAPDH & 58.0 & 96 & 99.009 & 0.997 & -3.346 \\
\hline
\end{tabular}

Table 1. Annealing temperature and qPCR efficiency of 10 candidate reference genes. Ta annealing temperature.

reference genes in different tissues of 120-day-old Hy-line brown layer hens, and showed that RPS 2 and $\beta$-actin genes had the highest relative stability. During the breeding period in geese, GAPDH is relatively stable both in the egg laying stage and before the onset of lay, while $18 \mathrm{~S}$ is relatively stable before the onset of lay and shows poor stability in the early egg laying stage ${ }^{14}$. In different tissues of the white king pigeon, the internal reference gene combination of RPS $2+18 S$ rRNA was found as most suitable for gene expression studies ${ }^{15}$. However, the systematic evaluation of reference genes in geese is still rare, especially in those subjected to light treatment. In this study, four algorithms were used to rank the applicability of 10 common reference genes in hypothalamus, pituitary and testis tissues of Magang geese under light treatmen. The results are expected to provide a reference for gene expression research in reproductive axis tissue of geese under light treatment.

\section{Results}

Primers specificity and efficiency. A total of 10 candidate genes were evaluated as potential reference genes in this study. The annealing temperature of each of the primers was confirmed by gradient PCR (Table 1). Specificity of each of the primers was confirmed by gel electrophoresis and dissociation curve analysis at the expected primer annealing temperature. All primers showed amplification in gel electrophoresis as single bands with the expected amplicon sizes (Fig. 1A), and single peaks in the melting curve analysis, confirming the specificity of the primer pairs (Fig. 1B).

To construct the standard curve, the logarithm of the copy number was considered the abscissa, and the $\mathrm{Ct}$ value was considered the ordinate. The efficiency of the primers ranged from 92.85 to $107.62 \%$ and $\mathrm{R}^{2}>0.98$ (Table 1).

Expression levels of candidate reference genes. For each candidate reference gene, Ct values were presented for the expression data from reproductive axis tissues. The results showed variability among the various reference candidate genes, with mean Ct values ranging from 15 to 25 (Fig. 2). The expression of GAPDH showed wide variation among different tissues, whereas the expression of $A C T B$ was relatively high and concentrated among different tissues.

Determination of expression stability of reference candidate genes. Stability in expression of the 10 candidate reference genes was determined using the mathematical algorithms Comparative $\Delta \mathrm{CT}$, geNorm, NormFinder and BestKeeper. The results of the $\triangle \mathrm{CT}$ method showed that the top two genes in the hypothalamic tissue of the Magang goose in the three breeding states were LDHA and TFRC; in pituitary tissue, TUBB4 and HPRT1; and in testicular tissue, HPRT1 and SDHA (Fig. 3A). The geNorm ranks genes according to their average expression stability (M). The more stable the expression, the lower the $\mathrm{M}$ value. To identify stable reference genes, the threshold of the geNorm $\mathrm{M}$ value was set to 1.5. With the exception of the stable value of SDHA gene in hypothalamic tissue, all genes displayed stability values below the accepted threshold. The results of the geNorm analysis showed that the top two genes in hypothalamic tissue of the Magang goose in three breeding stages were ACTB and RPL4; in pituitary tissue, SDHA and HPRT1; and in testicular tissue, LDHA and HPRT1 (Fig. 3B). The results of the NormFinder analysis were generally consistent with those of the geNorm analysis. However, the only exceptions in the NormFinder analysis were the second-ranked genes in hypothalamic and pituitary tissue, which were B2M and RPS2, respectively (Fig. 3C). In BestKeeper analysis, the best reference genes were those that had the lowest coefficient of variance and standard deviation (SD). Reference genes with a $\mathrm{SD}$ value $<1$ are considered stable. The results showed that the $S D H A$ gene $\mathrm{SD}>1$ in hypothalamic tissue did not meet the criteria for internal reference gene screening; thus, subsequent analysis was not performed. The top two genes in the hypothalamic tissue at the three breeding stages were $L D H A$ and TUBB4; in pituitary tissue, $L D H A$ and RPS2; and in testis tissue, ACTB and HPRT1 (Fig. 3D).

The results of the four algorithms enabled a comprehensive analysis, and the ranking of 10 candidate reference genes are summarized in Table 2. Among the reproductive axis tissues of Magang geese at different reproductive stages, the reference genes most suitable for hypothalamic tissues were ACTB and TUBB4, and the least stable reference genes were GAPDH and SDHA. As reference genes, both HPRT1 and RPL4 showed good stability in 


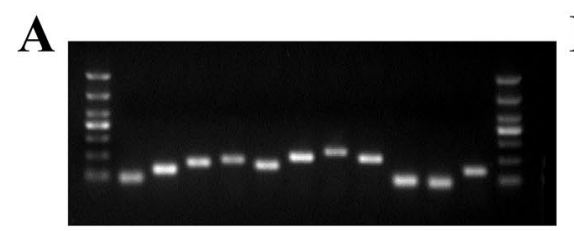

M $12 \begin{array}{llllllllllll} & 2 & 4 & 5 & 6 & 7 & 8 & 9 & 10 & 11 & M\end{array}$
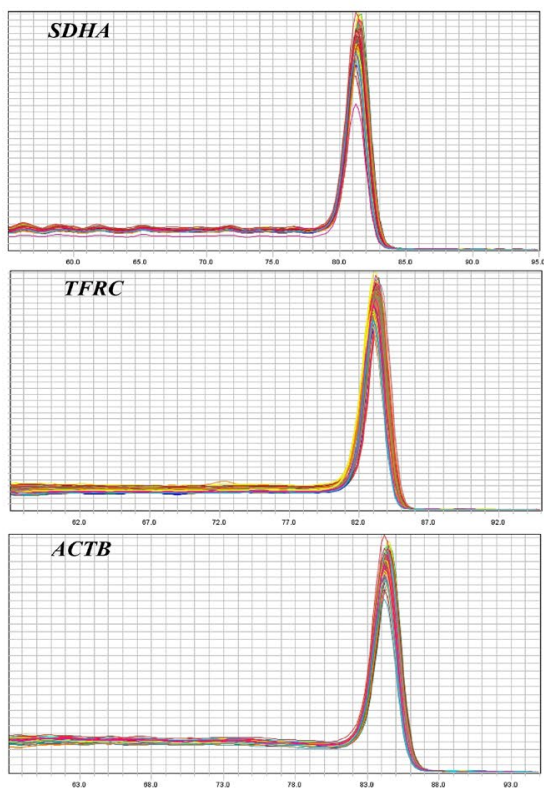
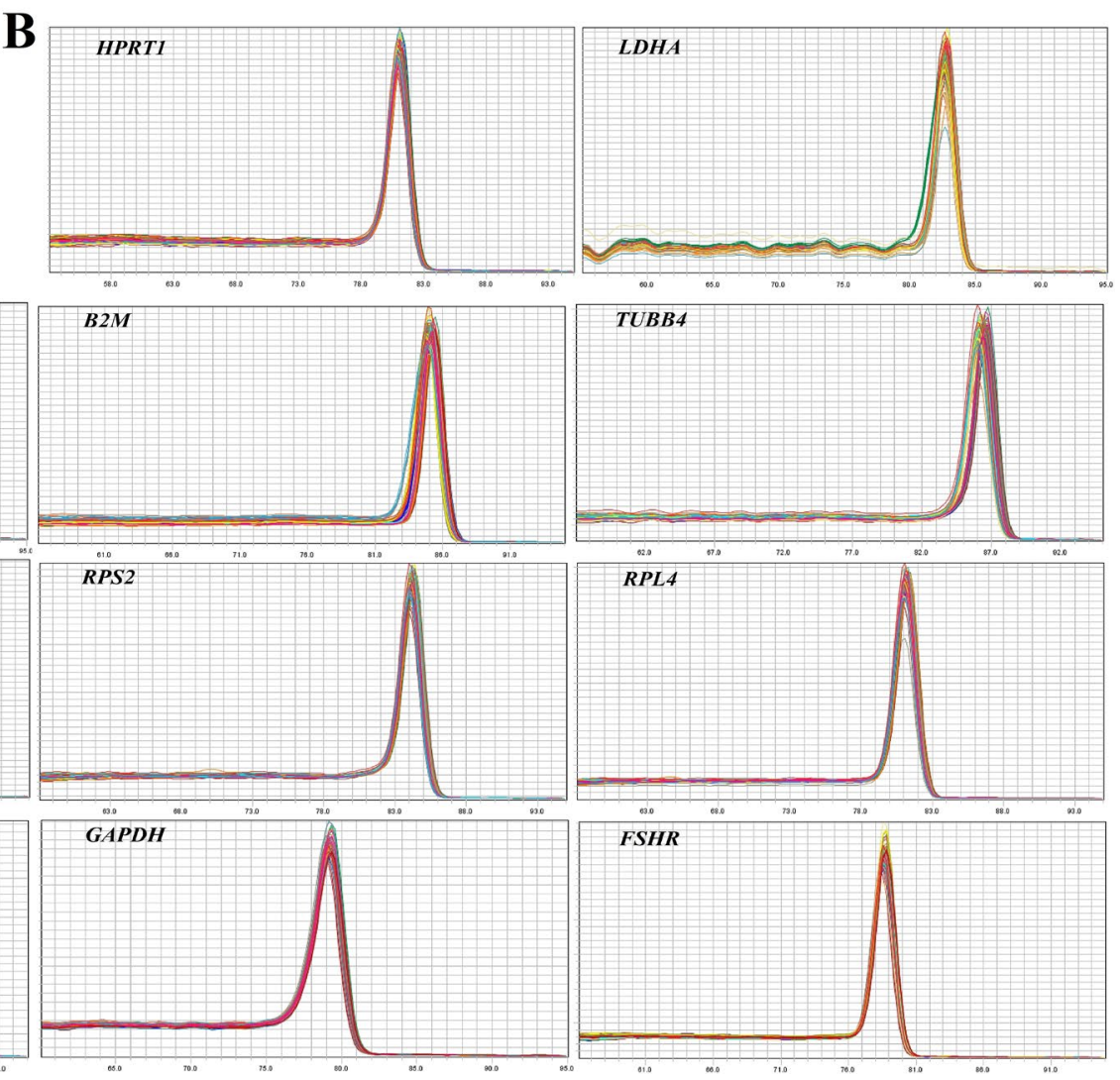

Figure 1. Primer specific detection of 10 candidate reference genes and verification gene FSHR. (A) PCR agarose gel electrophoresis; (B) Melting curves. M: DL1000 DNA marker; 1: HPRT1; 2: LDHA; 3: SDHA; 4: B2M; 5: TUBB4; 6: TFRC; 7: RPS2; 8: RPL4; 9: ACTB; 10: GAPDH; 11: FSHR.

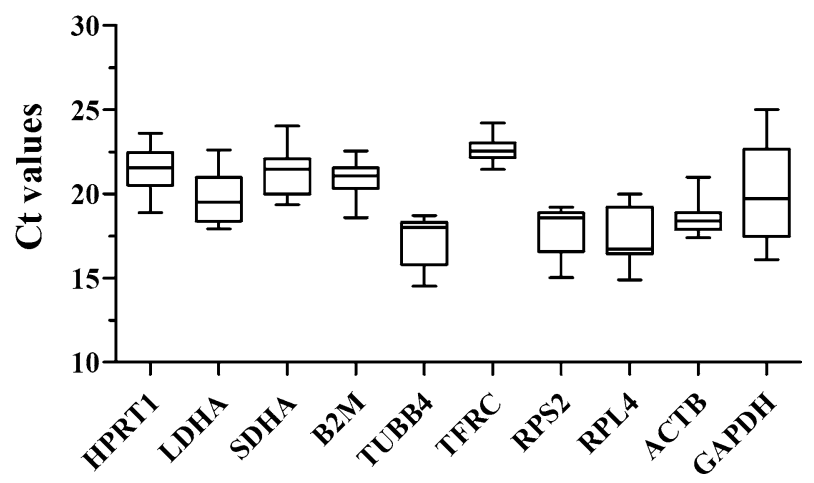

Figure 2. Cycle threshold $(\mathrm{Ct})$ variation in tissues of the reproductive axis of Magang geese during different reproductive stages.

pituitary tissues, whereas $A C T B$ and $G A P D H$ showed poor stability. In testicular tissue, the most stable internal reference genes were HPRT1 and $L D H A$, whereas B2M and TFRC were less stable. Among all three tissues, $A C T B$ was the most stable reference gene, and GAPDH was the least stable.

In order to more intuitively show optimal reference genes applicable to the hypothalamus, pituitary and testis, we constructed Venn diagrams using the top five reference genes among the four analyses conducted (Fig. 4). Based on the four software analyses combined, ACTB was the most suitable reference gene of the whole reproductive axis of Magang geese subjected to different light treatments and different reproductive conditions.

Determination of the optimal number of reference genes. The geNorm program can also use standardized factors to analyze paired differences to evaluate the optimal number of required internal reference genes. The $\mathrm{V}$ value is the pairwise variation of the normalization factor after introducing a new internal reference gene. When $\mathrm{Vn} / \mathrm{Vn}+1<0.15$, there is no need to introduce the next internal reference gene for correction, 
A

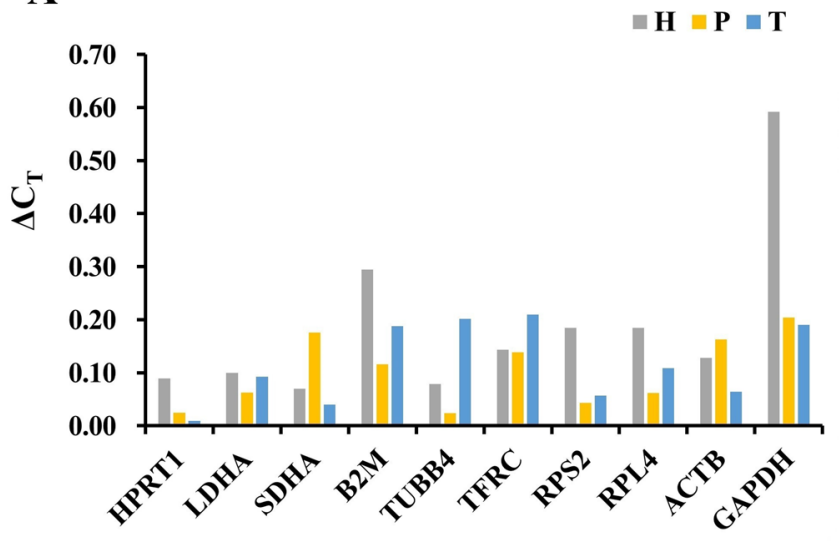

C

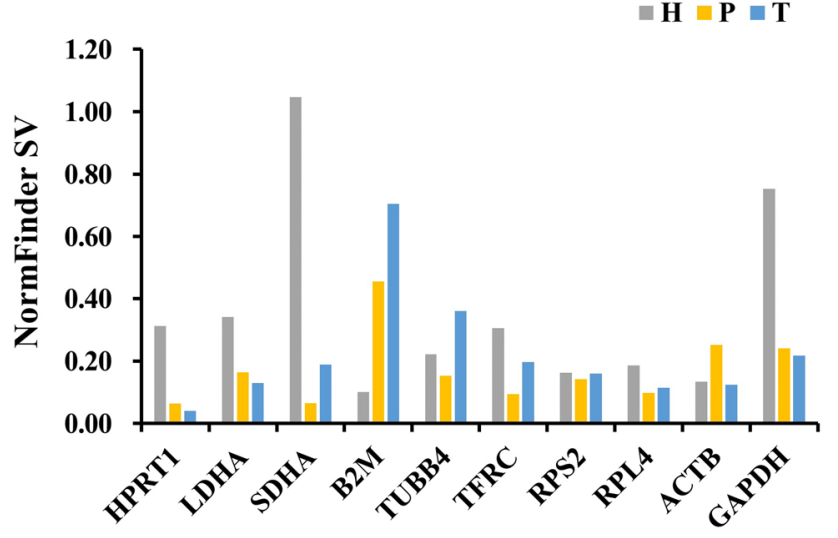

B

$\square \mathbf{H} \backsim \mathbf{P} \backsim \mathbf{T}$

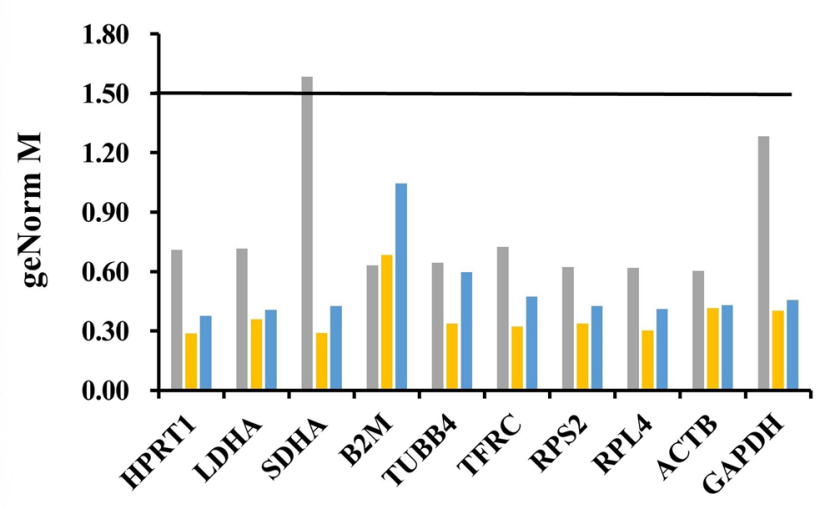

D

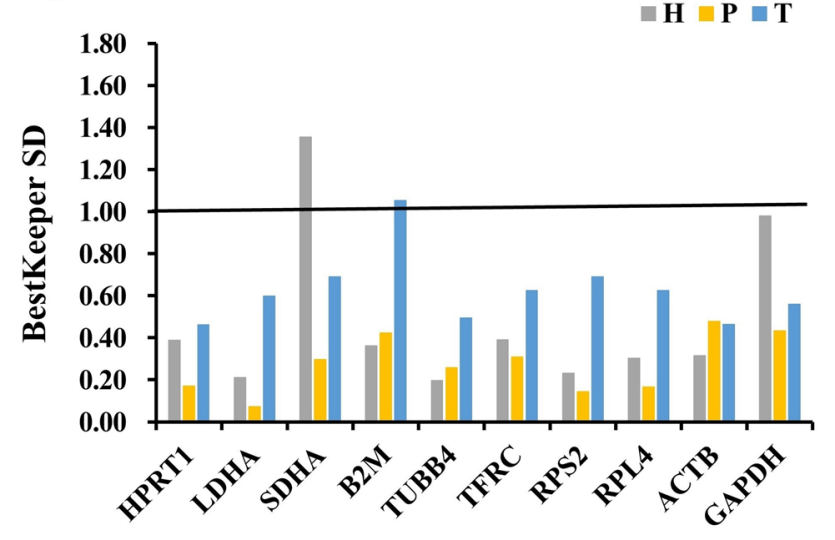

Figure 3. Analysis of reference gene stability based on different algorithms. (A) $\Delta \mathrm{Ct}$; (B) geNorm; (C) NormFinder; (D) BestKeeper. $H$ hypothalamus, $P$ pituitary, $T$ testis, $M$ Average expression stability, $S V$ stability value, $S D$ standard deviation.

and the optimal number of internal reference genes is $n$. When $V n / V n+1>0.15$, the next internal reference gene needs to be introduced for correction, and the optimal number of internal reference genes is $n+1^{16,17}$. The results showed that $\mathrm{V} 2 / \mathrm{V} 3<0.15$ in the hypothalamus, pituitary and testis, and therefore did not need the introduction of a third reference gene. Thus, the optimal number of reference genes was two (Fig. 5). Combined with the stability analysis of the aforementioned reference genes, ACTB and TUBB4; HPRT1 and RPL4; and HPRT1 and $L D H A$ can be used as optimal reference gene combinations in hypothalamic, pituitary, and testicular tissues during different reproductive stages.

Evaluation and validation of selected reference genes. To further verify the stability of the screened reference genes, two relatively stable reference genes (HPRT1 and LDHA) and ACTB were selected to analyze the expression patterns of FSHR genes in testicular tissues of the breeding and reproductive decay periods. Moreover, the less stable reference genes (B2M and TFRC) were selected as controls. When normalizing a stable internal reference gene, the combination of two internal reference genes and $A C T B$, as well as the expression of FSHR in the testis tissue of the reproductive decline period was significantly lower $(P<0.05)$ than that of the breeding period (Fig. 6). When using internal reference genes with the least stability, no significant difference was noted in the expression of FSHR during the reproductive decline period and the breeding period (Fig. 6).

\section{Discussion}

Quantitative PCR is one of the most powerful techniques used in the detection and determination of nucleic acid content in different types of samples. Therefore, it has a wide range of applications in the fields of life sciences, molecular diagnostics, agriculture and medicine ${ }^{18}$. Bustin ${ }^{3}$ pointed out that the selection of normalization genes is critical to the reliability of study findings. Lossos et al. ${ }^{19}$ showed that there is no single reference gene that can be applied to various cell types and different tissues. Therefore, it is necessary to screen suitable internal reference genes, especially for expression studies in some tissues that have been subjected to specific conditions.

It is generally believed that the amplification efficiency of qPCR between 90 and $110 \%$ is close to the ideal situation, and when the correlation coefficient $\mathrm{R}^{2}$ is greater than 0.98 , there is a good correlation between the two values. Through calculation, we found that the amplification efficiency of the 10 candidate reference genes ranged from 92.845 to $107.615 \%$, and the determination coefficient R2 ranged from 0.982 to 0.998 (Table 2), 


\begin{tabular}{|c|c|c|c|c|c|c|c|c|c|}
\hline \multirow[b]{2}{*}{ Group } & \multirow[b]{2}{*}{ Gene symbol } & \multicolumn{2}{|l|}{$\Delta \mathrm{Ct}$} & \multicolumn{2}{|c|}{ geNorm } & \multicolumn{2}{|c|}{ NormFinder } & \multicolumn{2}{|c|}{ Bestkeeper } \\
\hline & & Rank & $\Delta$ Ct value & Rank & M value & Rank & SV value & Rank & SD \\
\hline \multirow{10}{*}{ ALL } & HPRT1 & 3 & 0.043 & 9 & 2.100 & 9 & 1.344 & 4 & 0.941 \\
\hline & LDHA & 1 & 0.020 & 7 & 1.586 & 7 & 0.773 & 6 & 1.055 \\
\hline & SDHA & 6 & 0.071 & 5 & 1.436 & 2 & 0.527 & 5 & 0.942 \\
\hline & B2M & 8 & 0.090 & 2 & 1.407 & 3 & 0.538 & 3 & 0.717 \\
\hline & TUBB4 & 9 & 0.091 & 3 & 1.409 & 4 & 0.558 & 7 & 1.290 \\
\hline & TFRC & 2 & 0.040 & 6 & 1.507 & 6 & 0.734 & 2 & 0.459 \\
\hline & RPS2 & 7 & 0.078 & 4 & 1.421 & 5 & 0.578 & 8 & 1.354 \\
\hline & RPL4 & 5 & 0.062 & 8 & 1.684 & 8 & 0.868 & 9 & 1.447 \\
\hline & АСТВ & 4 & 0.050 & 1 & 1.304 & 1 & 0.363 & 1 & 0.445 \\
\hline & GAPDH & 10 & 0.228 & 10 & 2.300 & 10 & 1.465 & 10 & 2.098 \\
\hline \multirow{10}{*}{$\mathrm{H}$} & HPRT1 & 3 & 0.089 & 6 & 0.709 & 7 & 0.312 & 7 & 0.388 \\
\hline & LDHA & 4 & 0.100 & 7 & 0.715 & 8 & 0.340 & 2 & 0.211 \\
\hline & SDHA & 1 & 0.070 & 10 & 1.584 & 10 & 1.046 & 10 & 1.354 \\
\hline & B2M & 9 & 0.294 & 4 & 0.632 & 1 & 0.101 & 6 & 0.362 \\
\hline & TUBB4 & 2 & 0.079 & 5 & 0.644 & 5 & 0.222 & 1 & 0.197 \\
\hline & TFRC & 6 & 0.143 & 8 & 0.725 & 6 & 0.305 & 8 & 0.391 \\
\hline & \begin{tabular}{|l|} 
RPS2 \\
\end{tabular} & 8 & 0.185 & 3 & 0.623 & 3 & 0.163 & 3 & 0.231 \\
\hline & RPL4 & 7 & 0.184 & 2 & 0.618 & 4 & 0.185 & 4 & 0.303 \\
\hline & ACTB & 5 & 0.128 & 1 & 0.603 & 2 & 0.133 & 5 & 0.316 \\
\hline & GAPDH & 10 & 0.591 & 9 & 1.283 & 9 & 0.752 & 9 & \begin{tabular}{|l|}
0.979 \\
\end{tabular} \\
\hline \multirow{10}{*}{$\mathrm{P}$} & HPRT1 & 2 & 0.024 & 1 & 0.288 & 1 & 0.063 & 4 & 0.171 \\
\hline & LDHA & 5 & 0.062 & 7 & 0.358 & 7 & 0.163 & 1 & 0.073 \\
\hline & SDHA & 9 & 0.175 & 2 & 0.289 & 2 & 0.065 & 6 & 0.296 \\
\hline & B2M & 6 & 0.116 & 10 & 0.683 & 10 & 0.455 & 8 & 0.423 \\
\hline & TUBB4 & 1 & 0.024 & 5 & \begin{tabular}{|l|}
0.337 \\
\end{tabular} & 6 & \begin{tabular}{|l|}
0.153 \\
\end{tabular} & 5 & \begin{tabular}{|l|}
0.259 \\
\end{tabular} \\
\hline & TFRC & 7 & 0.138 & 4 & 0.323 & 3 & 0.093 & 7 & 0.309 \\
\hline & RPS2 & 3 & 0.043 & 6 & 0.337 & 5 & 0.141 & 2 & 0.144 \\
\hline & RPL4 & 4 & 0.062 & 3 & 0.303 & 4 & 0.098 & 3 & 0.166 \\
\hline & ACTB & 8 & 0.163 & 9 & 0.415 & 9 & 0.251 & 10 & 0.479 \\
\hline & GAPDH & 10 & 0.204 & 8 & 0.401 & 8 & 0.240 & 9 & 0.434 \\
\hline \multirow{10}{*}{$\mathrm{T}$} & HPRT1 & 1 & 0.009 & 1 & 0.377 & 1 & 0.040 & 1 & \begin{tabular}{|l|}
0.461 \\
\end{tabular} \\
\hline & LDHA & 5 & 0.092 & 2 & 0.406 & 4 & 0.129 & 5 & 0.598 \\
\hline & SDHA & 2 & 0.040 & 4 & 0.426 & 6 & \begin{tabular}{|l|l|}
0.189 \\
\end{tabular} & 8 & 0.690 \\
\hline & B2M & 7 & 0.188 & 10 & 1.046 & 10 & 0.705 & 10 & 1.053 \\
\hline & TUBB4 & 9 & 0.201 & 9 & \begin{tabular}{|l|}
0.597 \\
\end{tabular} & 9 & 0.359 & 3 & 0.495 \\
\hline & TFRC & 10 & 0.209 & 8 & 0.474 & 7 & \begin{tabular}{|l|}
0.197 \\
\end{tabular} & 7 & 0.625 \\
\hline & RPS2 & 3 & 0.057 & 5 & 0.427 & 5 & 0.160 & 9 & 0.690 \\
\hline & RPL4 & 6 & 0.109 & 3 & 0.411 & 2 & 0.115 & 6 & 0.624 \\
\hline & ACTB & 4 & 0.064 & 6 & 0.431 & 3 & 0.124 & 2 & 0.464 \\
\hline & GAPDH & 8 & 0.191 & 7 & 0.455 & 8 & 0.217 & 4 & 0.560 \\
\hline
\end{tabular}

Table 2. Expression stability analysis of each candidate reference gene for the reproductive axis tissues based on $\Delta \mathrm{Ct}$, geNorm, NormFinder and BestKeeper algorithms. $H$ hypothalamus, $P$ pituitary, $T$ testis, $M$ Average expression stability, $S V$ Stability Value, $S D$ Standard Deviation. With NormFinder and geNorm, low stability values indicate greater gene expression stability. With BestKeeper, genes with SD values greater than 1 are considered unstable.

indicating that each reference gene had a good linear relationship within the concentration gradient of serial dilution, and the data was valid.

Studies have been conducted on the screening of reference genes in various tissues of geese. In various stages of granular cells of the Tianfu goose, the three most stable internal reference genes were $S D H, H M B S$ and $18 S$, and the three least stable were $U B C, G A P D H$ and $T U B^{20}$. In $\mathrm{Zi}$ geese, GAPDH was a relatively suitable internal reference gene for expression analysis of target genes during the egg laying stage and before the onset of lay. Ji et al. ${ }^{21}$ analyzed the stability of seven genes in five tissues of $\mathrm{Zi}$ geese and found that the expression of HPRT1 was the most stable in muscle, $28 \mathrm{~S}$ in the heart, GAPDH in the liver and ovaries, and ACTB in the kidney. In the current study, combining the results of four software analyses, we found that the optimal internal reference genes of various tissues of the Magang goose differ. The optimal internal reference gene combination in hypothalamic 


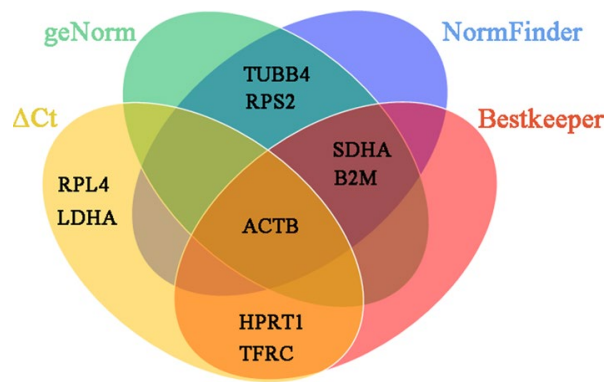

Figure 4. Venn diagrams of the top five internal reference genes derived from four software analyses of the entire reproductive axis.

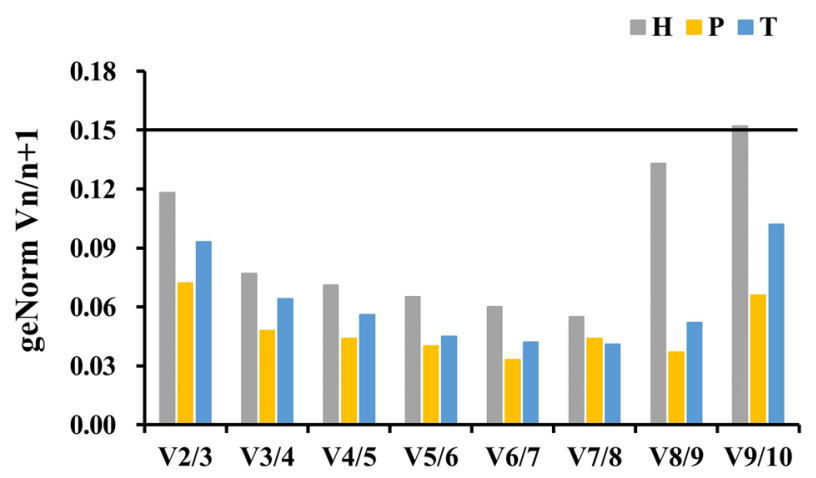

Figure 5. Determination of the optimal number of reference genes. $H$ hypothalamus, $P$ pituitary, $T$ testis.

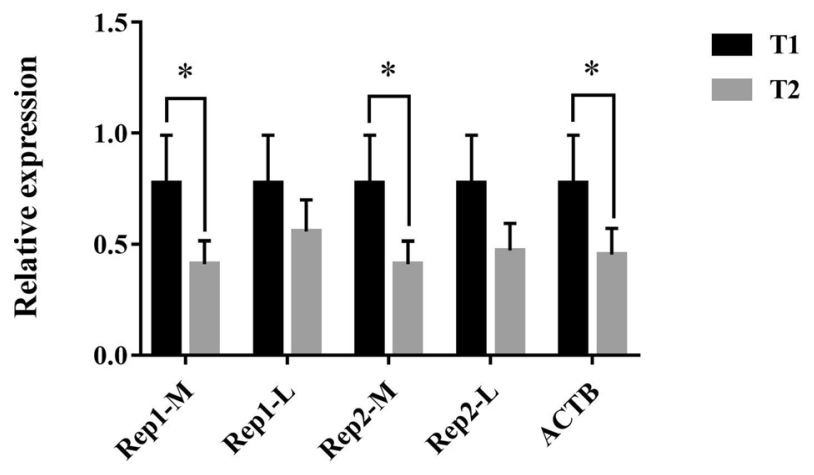

Figure 6. Validation of the selected reference genes by detected expression of the FSHR gene in the testis at different reproductive stages. T1 reproduction period, T2 reproduction decline period, Rep1-M/L the most stable (HPRT1) and least stable $(B 2 M)$ reference genes, Rep2-M/L the two most stable (HPRT1 and $L D H A)$ and two least stable $\left(B 2 M\right.$ and TFRC) reference gene combinations; ${ }^{\star} P<0.05$.

tissue is $A C T B$ and TUBB4, and the optimal internal reference gene combination in pituitary tissue is HPRT1 and RPL4. The most suitable internal reference gene combination in the testis is HPRT1 and LDHA.

As stated in the minimum information for publication of quantitative real-time PCR experiments (MIQE) guidelines $^{3}$, normalization of qPCR data using a single internal reference gene may lead to bias in the results; therefore, the use of two or more reference genes is recommended. The optimal number of required reference genes can be evaluated according to the geNorm procedure. If $\mathrm{Vn} / \mathrm{n}+1$ is below the threshold of 0.15 , the benefits of using additional $(n+1)$ reference genes will be limited. Previous studies have shown that the optimal number of reference genes required is two, in tissues of skeletal muscle, the spleen, and shell gland of chickens ${ }^{12,22,23}$. In the current study, the geNorm $\mathrm{V}$ value of the two most stably expressed reference genes in the hypothalamus, pituitary, and testis was $<0.15$. Thus, the addition of a third stable gene was not necessary to normalize the expression data.

As stated in the MIOE guidelines ${ }^{3}$, normalization of qPCR data using a single internal reference gene may lead to bias in results, so it is recommended to use two or more reference genes. The optimal number of required 
reference genes can be evaluated according to geNorm procedure. Once $\mathrm{Vn} / \mathrm{n}+1$ is below the threshold of 0.15 , the benefits of using additional $(n+1)$ reference genes will be limited. Many studies found that the optimal number of required reference genes was two. Such as in skeletal muscle, spleen and shell gland of chickens ${ }^{11,24}$. In this study, the geNorm $\mathrm{V}$ of the two most stably expressed reference genes in hypothalamus, pituitary and testis was $<0.15$, so it was not necessary to add a third stable gene to normalize the expression data.

Based on the analysis of the data from the three tissues, the ACTB gene ranked in the top five of the four software analyses, whereas GAPDH was found to have poor stability. GAPDH is involved in glycolytic pathways, and its expression depends on tissue type and specific conditions ${ }^{22}$, such as glucose deprivation and stress induction ${ }^{25}$. Recently, GAPDH has been found to be the most unstable reference gene in white adipose tissue and skeletal muscle in the inguinal adipose tissue of food-restricted mice ${ }^{26}$. In the current study, GAPDH ranked the highest with most statistical tools. Therefore, we suggest that GAPDH should not be used as a reference gene in geese subjected to light treatment.

FSHR was used as a target gene to validate our reference gene in the testis for qPCR. The combination of FSHR and FSH can promote Sertoli cells to produce inhibin and induce feedback inhibition of pituitary secretion and synthesis of FSH, and effectively stop spermatogenesis ${ }^{27}$. The reproductive characteristics of Magang goose are of short-day type. A lot of studies and practices have shown that long-day light can cause Magang goose to stop laying. We treated Magang geese with continuous long light (18L:6D), and the geese entered the rest period after 25 days of light treatment. Samples were taken before the initiation of light treatment (the breeding period); and at 14 days (breeding decay period); and 28 days (rest period) after light treatment. From the data analysis results, it can be seen that from the breeding period to the reproductive decline period, the expression level of FSHR in Magang geese should be significantly reduced. The two most stable and two most unstable internal reference genes were used for verification. The results showed that the most unstable gene significantly affected the results of normalization of expression data and might lead to misinterpretation of these data.

In summary, the optimal reference genes differed in various tissues of the reproductive axis of Magang geese subjected to light treatment. A combination of the two most stable reference genes was a more effective screening strategy. Use of the $A C T B$ gene is recommended in the study of gene expression in tissues of the reproductive axis of Magang geese subjected to various light treatments.

\section{Methods}

Ethics statement. The experimental setup was approved by the Animal Care Committee of the Zhongkai University of Agriculture and Engineering in China. All applicable institutional and governmental regulations concerning the ethical use of animals were followed, and all efforts were made to minimize animal suffering.

Animals. The study was conducted at a goose farm in Qingyuan, Guangdong province from October 1 to November 1, 2019. A total of 420 (male:female=1:5) 3-year-old Magang geese during the normal breeding period were selected. The geese were exposed to natural light (13L:11D) before the study commenced, and were then treated with light on October 1. The duration of light was gradually extended to $18 \mathrm{~L}: 6 \mathrm{D}$ after October 3, and the geese entered the rest period after 25 days of light treatment. Eight male geese were randomly selected one day before the initiation of light treatment (the breeding period); and at 14 days (breeding decay period); and 28 days (rest period) after light treatment. The experimental animals were humanely euthanized, and the hypothalamic, pituitary, and testis tissues were collected. The tissue samples were rinsed with diethylpyrocarbonate (DEPC) water and put into a cryopreservation tube, and then quickly placed in a liquid nitrogen tank for cryopreservation, and stored at $-80^{\circ} \mathrm{C}$.

RNA isolation and CDNA synthesis. The total RNA of the goose hypothalamus, pituitary and testis was extracted by the magnetic bead method (Xian Tianlong Technology, China), and the concentration and purity of total RNA were detected using an Epoch microplate spectrophotometer (BioTek, USA). The RNA integrity was determined by 1.0\% agar-gel electrophoresis. The cDNA was synthesized using the ReverTra Ace qPCR RT Master Mix with gDNA Remover (Code No. FSQ-301), following the recommended manufacturer's protocol (TOYOB, Shanghai) and stored at $-20^{\circ} \mathrm{C}$.

Reference gene selection and primers optimization. A total of 10 genes (HPRT1, GAPDH, ACTB, $L D H A, S D H A, B 2 M, T U B B 4, T F R C, R P S 2$, and RPL4) were selected as candidate internal reference genes for analysis of expression stability. Reference genes were chosen based on the literature, and nucleotide sequences were recovered from GenBank (www.ncbi.nlm.nih.gov/genbank/). All primers were designed using the Premier Primer 5.0 software (Premier Bio-soft International, CA, USA) and synthesized by Sangon Biotech Co. Ltd (Shanghai, China). Primer BLAST was used for detection to confirm the specificity of primer sequences, and primer dimers and hairpin structures were verified. The primer data of the candidate internal reference genes are presented in Table 3.

Each primer pair was subjected to the PCR and then detected by $1.5 \%$ agarose gel electrophoresis and DNA sanger sequencing. The PowerUp SYBR Green Master Mix fluorescent quantitative kit (Invitrogen, CA, USA) and QuantStudio 7 Flex real-time PCR detection system (Applied Biosystems, CA, USA) were used for quantitative analysis of the RT-qPCR. The cDNA template was diluted into six gradients $\left(1,10^{-1}, 10^{-2}, 10^{-3}, 10^{-4}\right.$, and $\left.10^{-5}\right)$, and $\mathrm{qPCR}$ detection was performed with these serial gradient concentrations of the cDNA template.

The following experimental RT-qPCR conditions were used: one cycle at $95^{\circ} \mathrm{C}$ for $10 \mathrm{~min} ; 40$ cycles at $95^{\circ} \mathrm{C}$ for $10 \mathrm{~s}$; and $60 \mathrm{~s}$ at $60^{\circ} \mathrm{C}-62^{\circ} \mathrm{C}$. Additional steps with a gradual increase in temperature from 60 to $62{ }^{\circ} \mathrm{C}$ up to $95^{\circ} \mathrm{C}$ were used to obtain a dissociation curve. The data were analyzed using the ABI 7500 software v2.3 software 


\begin{tabular}{|c|c|c|c|c|}
\hline No. & Gene symbol & Gene name & Accession no. & Primer sequence $\left(5^{\prime}-3^{\prime}\right)$ \\
\hline 1 & HPRT1 & Hypoxanthine phosphoribosyltransferase & AJ132697 & $\begin{array}{l}\text { F: GCACTATGACTCTACCGACTATTG } \\
\text { R: CAGTTCTGGGTTGATGAGGTT }\end{array}$ \\
\hline 2 & LDHA & Lactatedehydro-genase A & ENSGALE00000067556 & $\begin{array}{l}\text { F: CTATGTGGCCTGGAAGATCAG } \\
\text { R: GCAGCTCAGAGGATGGATG }\end{array}$ \\
\hline 3 & SDHA & $\begin{array}{l}\text { Succinate dehydrogenase complex, subunit } \\
\text { A }\end{array}$ & XM_013195307.1 & $\begin{array}{l}\text { F: AAAAGGAGGACAGGCTCACA } \\
\text { R: ACACCACGACACTCTCCATT }\end{array}$ \\
\hline 4 & B2M & Beta-2-microglobulin & XM_013198887.1 & $\begin{array}{l}\text { F: GTCCTCAACTGCTACGTGGA } \\
\text { R: AGGTGTAGACGTCGCTCTTG }\end{array}$ \\
\hline 5 & TUBB4 & Tubulin beta- 4 chain & XM_013182843.1 & $\begin{array}{l}\text { F: CTGGCAGTCAACATGGTTCC } \\
\text { R: ACATACGGCCCCTAAACACA }\end{array}$ \\
\hline 6 & TFRC & Transferrin receptor (p90, CD71) & XM_013195023.1 & $\begin{array}{l}\text { F: GAAGTGGCAAGTGTGAGGTG } \\
\text { R: ATCTTCACTCTGGCCAGCTT }\end{array}$ \\
\hline 7 & RPS2 & Ribosomal protein S2 & XM_013174975.1 & $\begin{array}{l}\text { F: TCCCAAGAAGCTGCTGATGA } \\
\text { R: TCTGCACTGAGACTCTGGTG }\end{array}$ \\
\hline 8 & RPL4 & Ribosomal protein $\mathrm{L} 4$ & XM_013193267.1 & $\begin{array}{l}\text { F: GCAAACCCGCTACTCTGAAG } \\
\text { R: TTTTGGCGTACGGGTTCAAC }\end{array}$ \\
\hline 9 & АСТВ & $\beta$-Actin & M26111 & $\begin{array}{l}\text { F: CAACGAGCGGTTCAGGTGT } \\
\text { R: TGGAGTTGAAGGTGGTCTCG }\end{array}$ \\
\hline 10 & GAPDH & $\begin{array}{l}\text { Glyceraldehyde-3-phosphate dehydro- } \\
\text { genase }\end{array}$ & DQ821717.1 & $\begin{array}{l}\text { F: GCTGATGCTCCCATGTTCGTGAT } \\
\text { R: GTGGTGCAAGAGGCATTGCTGAC }\end{array}$ \\
\hline 11 & VIP & Vasoactive intestinal peptide & XM_013178196.1 & $\begin{array}{l}\text { F: TTGATGCAGCCAGTGAACCT } \\
\text { R: TTCCGAAAGCGGCTGTAGTT }\end{array}$ \\
\hline 12 & FSHR & Follicle stimulating hormone receptor & XM_013192472.1 & $\begin{array}{l}\text { F: GATGAGCAACCTGGCAATAAG } \\
\text { R: GGTGAGCAAGCCACATTAAC }\end{array}$ \\
\hline
\end{tabular}

Table 3. Primer information of candidate internal reference genes and target genes.

to generate standard curves and melting curves of the genes. The following formula $\mathrm{E}=\left(10^{-1} /\right.$ slope -1$) \times 100$ was used to calculate the PCR amplification efficiency of each target gene and reference gene $e^{3,28,29}$.

Quantitative real-time PCR. The expression of 10 genes in different tissues of eight individual geese at each stage were analyzed using qPCR with a $20 \mu \mathrm{L}$ reaction system as follows: SYBR Master Mix $10 \mu \mathrm{L}$; ddH2O $8.6 \mu \mathrm{L}$; upstream and downstream primers each, $0.2 \mu \mathrm{L}$; and cDNA template, $1 \mu \mathrm{L}$. Each sample was assayed in triplicate under the following conditions: The reaction conditions were as follows: pre-denaturation at $95^{\circ} \mathrm{C}$ for $30 \mathrm{~s}$; denaturation at $95^{\circ} \mathrm{C}$ for $5 \mathrm{~s}$; annealing at $60^{\circ} \mathrm{C}$; extension for $30 \mathrm{~s}$, over 40 cycles.

Determination of expression stability of reference genes. The stability of candidate reference genes was comprehensively evaluated using four methods: $\Delta \mathrm{CT}$, geNorm, NormFinder, and BestKeeper ${ }^{8-10,30}$. The relative expression level was calculated by the $2^{-\Delta \mathrm{Ct}}$ method $(\Delta \mathrm{Ct}=\mathrm{Ct}$, sample $-\mathrm{Ct}$, min). The gene showing the least expression among all the samples was first identified, and its $\mathrm{Ct}$ value (highest expression quantity) was determined. That lowest $\mathrm{Ct}$ value was then subtracted from the $\mathrm{Ct}$ value of a given sample gene, and the obtained $\Delta \mathrm{Ct}$ value was typically 0 or higher. After obtaining the $\Delta \mathrm{Ct}$ value of each gene of each sample, the Excel 2003 software was used to calculate the $2^{-\Delta \mathrm{Ct}}$ value of each corresponding gene for each corresponding sample. This value represented the relative quantitative data of each candidate internal reference gene, which was also used in the analysis of geNorm software data.

GeNorm software analysis was first used to calculate the relative quantitative data of each reference gene by the $2^{-\Delta \mathrm{Ct}}$ method. A table constructed with the Excel software was then imported into the geNorm program for further calculations. The $\mathrm{M}$ values of stability were derived for each internal reference gene, to determine the more suitable gene. Those with values lower than 1.5 were considered stable genes ${ }^{31,32}$. The calculation methods of the NormFinder program analysis were similar to those of the geNorm program. Both are based on the $2^{-\Delta \mathrm{Ct}}$ method to calculate the relative quantitative data of internal reference genes. The BestKeeper program used a built-in formula to calculate the SD of the pairing between each reference gene. Judgment criteria were as follows: the smaller the $\mathrm{SD}$ value, the better the stability of the internal reference gene, and if the $\mathrm{SD}>1$, the gene was considered unstable ${ }^{33,34}$. The $\Delta \mathrm{CT}$ method was used to calculate the average SD of each gene to determine the stability of the internal reference gene. The smaller the s value, the higher the stability of the gene. As each method is based on different algorithms, the results obtained may also differ.

In order to avoid any one-sidedness in the use of a single evaluation method, multiple evaluation methods can be combined for more comprehensive evaluations $s^{35}$. In the current study, the geometric mean of the evaluation rankings obtained by the four analysis methods was derived, and the stability of the reference genes was determined by the final comprehensive ranking index. The smaller the index, the more stable the expression of the reference genes.

Reference gene validation. In order to further verify the stability of the internal reference genes obtained through screening, the two most stable internal reference genes were selected to analyze the expression patterns of FSHR genes in tissues of the reproductive axis of Magang goose during different reproductive stages (breeding 
period, reproductive decline period, and rest period). Moreover, the most unstable internal reference genes were selected as the control group.

Received: 16 December 2020; Accepted: 19 March 2021

Published online: 07 April 2021

\section{References}

1. Higuchi, R., Dollinger, G., Walsh, P. S. \& Griffith, R. Simultaneous amplification and detection of specific DNA sequences. Nat. Biotechnol. 10, 413-417 (1992).

2. Huggett, J., Dheda, K., Bustin, S. \& Zumla, A. Real-time RTPCR normalisation: Strategies and considerations. Genes Immun. 6, 279-284 (2005).

3. Bustin, S. A. et al. The MIQE guidelines: Minimum information for publication of quantitative real-time PCR experiments. Clin. Chem. 55, 611-622 (2009).

4. Vandesompele, J. et al. Accurate normalization of real-time quantitative RT-PCR data by geometric averaging of multiple internal control genes. Genome Biol. 3, 1-34 (2002).

5. Wong, M. L. \& Medrano, J. F. Real-time PCR for mRNA quantitation. Biotechniques 39, 75 (2005).

6. Lee, P. D., Sladek, R., Greenwood, C. M. \& Hudson, T. J. Control genes and variability: Absence of ubiquitous reference transcripts in diverse mammalian expression studies. Genome Res. 12, 292-297 (2002).

7. Thellin, O. et al. Housekeeping genes as internal standards: Use and limits. J. Biotechnol. 75, 291-295 (1999).

8. Greer, S., Honeywell, R., Geletu, M., Arulanandam, R. \& Raptis, L. Housekeeping genes; expression levels may change with density of cultured cells. J. Immunol. Methods 355, 76-79 (2010).

9. Andersen, C. L., Jensen, J. L. \& Ørntof, T. F. Normalization of real-time quantitative reverse transcription-PCR data: A model-based variance estimation approach to identify genes suited for normalization, applied to bladder and colon cancer data sets. Can. Res. 64, 5245 (2004).

10. Pfaf, M. W., Tichopad, A., Prgomet, C. \& Neuvians, T. P. Determination of stable housekeeping genes, diferentially regulated target genes and sample integrity: BestKeeper-Excel-based tool using pair-wise correlations. Biotech. Lett. 26, 509-515 (2004).

11. Nascimento, C. S. et al. Identification of suitable reference genes for real time quantitative polymerase chain reaction assays on pectoralis major muscle in chicken (Gallusgallus). PLoS ONE 10, e0127935 (2015).

12. Marciano, C. M. M., Ibelli, A. M. G., Peixoto, J. D. O., Savoldi, I. R. \& Ledur, M. C. Stable reference genes for expression studies in breast muscle of normal and white striping-affected chickens. Mol. Biol. Rep. 47, 45-53 (2020).

13. Zhang, R., Shi, X. L., Chen, C. G., Wen, G. L. \& Zhao, Z. H. Screening of internal reference genes for real-time fluorescent quantitative PCR to study gene expression in layer tissues. China Anim. Husb. Vet. Med. 44, 2226-2233 (2017) (in Chinese).

14. Ji, H. et al. Stability of endogenous reference genes in green-goose tissues during prelaying and laying periods. Sci. Agric. Sin. 45, 2260-2266 (2011) (in Chinese).

15. Chen, L. et al. Screening of RT-qPCR internal reference genes from different tissues of white feather king pigeon. Chin. J. Anim. Husb. 56, 77-82 (2020) (in Chinese).

16. Wu, J. Y. et al. Analysis method of systematically evaluating stability of reference genes using geNorm, NormFinder and BestKeeper. Modern Agric. Sci. Technol. 48, 278-281 (2017).

17. Fu, J. X. et al. Reference gene selection for quantitative real-time polymerase chain reaction (qRT-PCR) normalization in the gene expression of sweet osmanthus tissue. J. Zhejiang A\& $r$ Univ. 33, 727-733 (2016) (in Chinese).

18. qPCR \& RT-qPCR Applications. http://qrt-pcr-applications.info/. Accessed 30 March 2017.

19. Lossos, I. S. et al. Optimization of quantitative real-time RT-PCR parameters for the study of lymphoid malignancies. Leukemia 17, 789-795 (2003).

20. Mo, Y. L., Wang, Y. S. \& Wang, J. W. Selection of endogenous reference genes in granule cells at different stages of Tianfu meat goose maternal line. J. Zhejiang Univ. 45, 376-384 (2019) (in Chinese).

21. Ji, H. et al. Selection of reliable reference genes for real-time qRT-PCR analysis of Zi Geese (Anser anser domestica) gene expression. Asian Austral. J. Anim. Sci. 26, 423-432 (2013).

22. Barber, R. D., Harmer, D. W., Coleman, R. A. \& Clark, B. J. GAPDH as a housekeeping gene: Analysis of GAPDH mRNA expression in a panel of 72 human tissues. Physiol. Genomics. 21, 389-395 (2005).

23. Zhang, Z. \& Hu, J. Development and validation of endogenous reference genes for expression profiling of medaka (Oryzias latipes) exposed to endocrine disrupting chemicals by quantitative real-time RT-PCR. Toxicol. Sci. 95, 356-368 (2007)

24. Khan, S., Roberts, J. \& Wu, S. B. Reference gene selection for gene expression study in shell gland and spleen of laying hens challenged with infectious bronchitis virus. Sci. Rep. 7, 14271 (2017).

25. Fink, T. et al. Instability of standard PCR reference genes in adipose-derived stem cells during propagation, differentiation and hypoxic exposure. BMC Mol. Biol. 9 , 98 (2008).

26. Gong, H. et al. Evaluation of candidate reference genes for RT-qPCR studies in three metabolism related tissues of mice after caloric restriction. Sci. Rep. 6, 37549 (2016).

27. Hu, N. et al. Regulatory effects of inhibin on spermatogenesis. J. Trad. Chin. Vet. Med. 35, 78-80 (2016) (in Chinese).

28. Tan, S. C. et al. Identification of valid housekeeping genes for quantitative RT-PCR analysis of cardiosphere-derived cells preconditioned under hypoxia or with prolyl-4-hydroxylase inhibitors. Mol. Biol. Rep. 39, 4857-4867 (2012).

29. Pfaffl, M. W. A new mathematical model for relative quantification in real-time RT-PCR. Nucleic Acids Res. 29, e45 (2001).

30. Silver, N., Best, S., Jiang, J. \& Thein, S. L. Selection of housekeeping genes for gene expression studies in human reticulocytes using real-time PCR. BMC Mol. Biol. 7, 33-33 (2006).

31. Wei, L. B. et al. Identification and testing of reference genes for sesame gene expression analysis by quantitative real-time PCR. Planta 237, 873-889 (2013).

32. José, V. D., Belén, R., Salvador, N. \& Clara, I. G. V. Evaluation of candidate reference genes for expression studies in Pisum sativum under different experimental conditions. Planta 232, 145-153 (2010).

33. Tu, L. L. et al. Suitable internal control genes in qRT-PCR normalization in cotton fiber development and somatic embryogenesis. Chin. Sci. Bull. 52, 2379-2385 (2007).

34. Li, H. Y. et al. De novo transcriptome of safflower and the identification of putative genes for oleosin and the biosynthesis of flavonoids. PLoS ONE 7, e30987 (2012).

35. Wang, Q. et al. Stability of endogenous reference genes in postmortem human brains for normalization of quantitative real-time PCR data: comprehensive evaluation using geNorm, NormFinder, and BestKeeper. Int. J. Legal Med. 126, 943-952 (2012).

\section{Acknowledgements}

National Natural Science Foundation of China (31902164 and 32072730); Natural Science Foundation of Guangdong Province (2018A030310009); Major Fundamental Research Project of Educational 
Department of Guangdong Province (2018KZDXM039); National Key Technologies R \& D Program of China (2016YFD0500510); The Pearl River S\&T Nova Program of Guangzhou (201906010040).

\section{Author contributions}

B.-B.Z. performed the gene expression experiments, analyzed and interpreted data, and drafed the manuscript; X.S. performed the animal trials; X.-J.L., analyzed and interpreted data; Y.-B.T., provided intellectual input, and contributed to the writing of the manuscript. H.-J.O.Y. and Y.-M.H.conceived and designed the study, wrote and revised the manuscript. All authors have read and approved the final manuscript.

\section{Competing interests}

The authors declare no competing interests.

\section{Additional information}

Correspondence and requests for materials should be addressed to H.-J.O. or Y.-M.H.

Reprints and permissions information is available at www.nature.com/reprints.

Publisher's note Springer Nature remains neutral with regard to jurisdictional claims in published maps and institutional affiliations.

(c) (i) Open Access This article is licensed under a Creative Commons Attribution 4.0 International

License, which permits use, sharing, adaptation, distribution and reproduction in any medium or format, as long as you give appropriate credit to the original author(s) and the source, provide a link to the Creative Commons licence, and indicate if changes were made. The images or other third party material in this article are included in the article's Creative Commons licence, unless indicated otherwise in a credit line to the material. If material is not included in the article's Creative Commons licence and your intended use is not permitted by statutory regulation or exceeds the permitted use, you will need to obtain permission directly from the copyright holder. To view a copy of this licence, visit http://creativecommons.org/licenses/by/4.0/.

(C) The Author(s) 2021 